\title{
P2X7 receptor regulates EMMPRIN and MMP-9 expression through AMPK/MAPK signaling in PMA-induced macrophages
}

\author{
LU LIN, SHANJUN HUANG, ZHOUYANG ZHU, JIBO HAN, \\ ZHENGXIAN WANG, WEIJIAN HUANG and ZHOUQING HUANG
}

\begin{abstract}
The Key Laboratory of Cardiovascular Disease of Wenzhou, Department of Cardiology, Cardiac Center, The First Affiliated Hospital of Wenzhou Medical University, Wenzhou, Zhejiang 325000, P.R. China
\end{abstract}

Received January 12, 2017; Accepted November 20, 2017

DOI: $10.3892 / \mathrm{mmr} .2018 .9282$

\begin{abstract}
The rupture of atherosclerotic plaques may result in the formation of thrombi, which may induce subsequent cardiac events such as acute myocardial infarction. Overproduction of matrix metalloproteinases (MMPs) and extracellular matrix metalloproteinase inducers (EMMPRINs) by monocytes and macrophages may lead to rupture of atherosclerotic plaques as a result of the degradation of the extracellular matrix. The purinergic $2 \mathrm{X} 7$ receptor $(\mathrm{P} 2 \mathrm{X} 7 \mathrm{R})$ is expressed in macrophages that are assembled in atherosclerotic lesions of human carotid arteries. P2X7R may serve a crucial role in the development of atherosclerosis; therefore, the present study aimed to determine whether P2X7R regulated the expression of EMMPRIN and MMP-9 in phorbol 12-myristate 13-acetate (PMA)-induced macrophages. In addition, the potential molecular mechanisms involved in this process were investigated. THP-1 human monocytic cells were pretreated with A-438079 (a specific inhibitor of P2X7R) for $1 \mathrm{~h}$ and subsequently incubated with or without PMA for $48 \mathrm{~h}$. Exposure to A-438079 significantly decreased the expression of MMP-9 and EMMPRIN in the PMA-induced macrophages and attenuated the activation (phosphorylation) of mitogen-activated protein kinase (MAPK) signaling, including c-Jun N-terminal kinase, p38 and extracellular signal-regulated kinase. The present study also demonstrated that 5'-AMP-activated protein kinase (AMPK) was activated by PMA exposure during differentiation from monocytes to macrophages. This activation was reversed by A-438079 treatment through the inhibition of P2X7R
\end{abstract}

Correspondence to: Dr Weijian Huang or Dr Zhouqing Huang, The Key Laboratory of Cardiovascular Disease of Wenzhou, Department of Cardiology, Cardiac Center, The First Affiliated Hospital of Wenzhou Medical University, 2 Fuxue Road, Wenzhou, Zhejiang 325000, P.R. China

E-mail: weijianhuang69@126.com

E-mail: susiehzq@126.com

Key words: purinergic $2 \mathrm{X} 7$ receptor, extracellular matrix metalloproteinase inducer, atherosclerosis, matrix metalloproteinase 9, 5'-AMP-activated protein kinase, mitogen-activated protein kinase expression. These results suggested that the inhibition of P2X7R may be able to suppress the AMPK/MAPK signaling pathway and consequently downregulate both EMMPRIN and MMP-9 expression in PMA-induced macrophages.

\section{Introduction}

Atherosclerosis may lead to ischemia of the heart, brain or extremities and may further lead to infarction, which is the primary cause of mortality in the United States, Europe and much of Asia (1). The stability of plaques in coronary arteries is of great importance, as the rupture of plaques may lead to fatal complications such as myocardial infarction.

Purinergic $2 \mathrm{X} 7$ receptor $(\mathrm{P} 2 \mathrm{X} 7 \mathrm{R})$ is a ligand-gated cation channel that is expressed by most immune cells such as macrophages, monocytes and lymphocytes (2). P2X7R is a member of the purinergic receptor family that is involved in the production and activation of the inflammatory cytokine interleukin (IL)-1 $\beta$ and modulates the inflammatory response (3). A previous study demonstrated that P2X7R was highly expressed in endothelial cells and macrophages that infiltrate atherosclerotic plaques of human carotid arteries (4); in addition, P2X7R serves a crucial role in the development of atherosclerosis by regulating the activation of the NACHT, LRR and PYD domains-containing protein 3 (NLRP3) inflammasome (5).

Matrix metalloproteinase (MMP)-9 is a $92 \mathrm{kDa}$ protein that belongs to a family of zinc- and calcium-dependent proteases (6). MMP-9 is considered to have various pathological functions. A number of studies have demonstrated the key role of MMP-9 in atherosclerosis was in the rupture of plaques through the degradation of the extracellular matrix $(7,8)$. Extracellular matrix metalloproteinase inducer (EMMPRIN; also known as CD147 or basigin) is a highly glycosylated transmembrane protein that was first described in tumor cells (9). Previous studies have demonstrated that EMMPRIN, as an upregulator of local MMP-9 expression (10), was involved in numerous physiological and pathological processes, including tumor invasion (9) and atherosclerosis (11). It has also been indicated that during differentiation from monocytes into macrophages, the expression of EMMPRIN and MMP-9 is significantly increased (12), thereby accelerating the transition of stable plaques into unstable plaques through atherogenic 
cells (13). Consequently, downregulation of EMMPRIN and MMP-9 expression may ameliorate the development of atherosclerosis. Notably, several studies have revealed that P2X7R regulates the expression of MMP-9 and that P2X7R is involved in fibrosis progression in the lungs (14) and liver (15). Upon ATP stimulation, P2X7R in human peripheral blood mononuclear cells was reported to mediate MMP-9 activities by rapidly increasing the release of MMP-9 and decreasing the release of tissue inhibitor of metalloproteinases 1 (TIMP-1) (16). However, whether P2X7R expressed in phorbol 12-myristate 13-acetate (PMA)-induced THP-1 cells is able to regulate EMMPRIN and MMP-9 expression remains unexplored.

AMPK is a cellular energy sensor that acts as a kinase to maintain various processes of energy homoeostasis, such as fatty acid oxidation, protein synthesis and glucose uptake (17-19). Our previous study demonstrated that the inhibition of AMPK $\alpha$ with compound C (a specific AMPK inhibitor) reduced MMP-9 and EMMPRIN expression levels in PMA-induced THP-1 cell differentiation, which suggested that activation of the AMPK $\alpha$ pathway may be involved in the regulation of EMMPRIN and MMP-9 expression in PMA-induced macrophages (20). Moreover, a number of previous studies have reported that MAPK signaling pathways are special regulators for EMMPRIN and MMP-9 $(21,22)$. On the basis of these results, the present study hypothesized that AMPK $\alpha$ and MAPK signaling pathways may regulate the levels of EMMPRIN and MMP-9 expression. However, whether P2X7R regulate the activation of AMPK $\alpha$ and MAPK signaling pathways is still unknown.

Therefore, the present study aimed at exploring the role of P2X7R in mediating the expression of EMMPRIN and MMP-9 in PMA-induced THP-1 cells and to further reveal its mechanisms.

\section{Materials and methods}

Cell culture and treatment. The human monocytic cell line THP-1 was obtained from American Type Culture Collection (Manassas, VA, USA) and maintained at a density of $10^{6}$ cells $/ \mathrm{ml}$ as the control group in RPMI-1640 medium (Thermo Fisher Scientific, Inc., Waltham, MA, USA) containing 10\% fetal bovine serum (Gibco; Thermo Fisher Scientific, Inc.), $10 \mathrm{mM}$ 4-(2-hydroxyethyl)-1piperazineethanesulphonic acid (Sigma-Aldrich; Merck KGaA, Darmstadt, Germany) and $1 \%$ penicillin/streptomycin solution at $37^{\circ} \mathrm{C}$ in a $5 \% \mathrm{CO}_{2}$ incubator. Cells were cultured in six-well at a density of $10^{6}$ cells $/ \mathrm{ml}$ for $48 \mathrm{~h}$ at $37^{\circ} \mathrm{C}$ in the presence of $100 \mathrm{nM}$ PMA (20), which allowed them to differentiate into adherent macrophages. Cells were pretreated with $100 \mu \mathrm{M}$ A-438079 (Selleck Chemicals, Houston, TX, USA) for $1 \mathrm{~h}$ at $37^{\circ} \mathrm{C}(23)$, and then stimulated with $100 \mathrm{nM}$ PMA for another $48 \mathrm{~h}$ at $37^{\circ} \mathrm{C}$, which was added directly to the medium.

Protein isolation and western blot analysis. Following treatment, cells were washed with cold PBS ( $\mathrm{pH} 7.4)$ and cell pellets were lysed for $30 \mathrm{~min}$ with a lysis buffer (0.5\% Nonidet P-40; $50 \mathrm{mmol} / 1$ Tris- $\mathrm{HCl}, \mathrm{pH} 7.5 ; 1 \mathrm{mmol} / \mathrm{l}$ EDTA; $1 \mathrm{mmol} / 1 \mathrm{EGTA}$ and $150 \mathrm{mmol} / \mathrm{l} \mathrm{NaCl}$; containing $10 \%$ glycerol; $50 \mathrm{mmol} / 1$ sodium fluoride; $10 \mathrm{mmol} / 1$ sodium pyrophosphate; $1 \mathrm{mmol} / 1$ sodium orthovanadate; $80 \mu \mathrm{mol} / \mathrm{l}$ $\beta$-glycerophosphate; $1 \mathrm{mmol} / 1$ phenylmethylsulfonyl fluoride; $10 \mu \mathrm{g} / \mathrm{ml}$ aprotinin; $100 \mu \mathrm{g} / \mathrm{ml}$ soybean trypsin inhibitor and $10 \mu \mathrm{g} / \mathrm{ml}$ leupeptin), followed by centrifugation at $4^{\circ} \mathrm{C}$ for $10 \mathrm{~min}$ at $12,000 \mathrm{x} \mathrm{g}$. Protein concentrations were measured by BCA protein assay (Pierce; Thermo Fisher Scientific, Inc., Waltham, MA, USA). The protein extracts were denatured and the solubilized proteins $(20 \mu \mathrm{g})$ subjected to electrophoresis by $10 \%$ SDS-PAGE. Proteins were subsequently transferred onto polyvinylidene difluoride membranes (EMD Millipore, Billerica, MA, USA). Membranes were blocked with TBS containing $0.05 \%$ Tween-20 (TBST) and 5\% skimmed milk for $1 \mathrm{~h}$ at room temperature, followed by probing with primary antibodies against GAPDH (cat. no. 5174), P2X7R (cat. no. 13809), matrix metalloproteinase (MMP)-9 (cat. no. 13667), 5'-AMP-activated protein kinase (AMPK) $\alpha$ (cat. no. 5832), phosphorylated (p)-AMPK $\alpha$ (cat. no. 50081), p38 (cat. no. 8690), p-p38 (cat. no. 9215), c-Jun N-terminal kinase (JNK) (cat. no. 9252), p-JNK (cat. no. 9255) (all 1:1,000 in TBST; Cell Signaling Technology, Inc., Danvers, MA, USA), EMMPRIN (1:1,000 in TBST; cat. no. ab666, Abcam, Cambridge, MA, USA), extracellular signal-regulated kinase (ERK)1/2 (cat. no. sc81457) or p-ERK1/2 (cat. no. sc81492) (both 1:300 in TBST; Santa Cruz Biotechnology, Inc., Dallas, TX, USA) at $4^{\circ} \mathrm{C}$ overnight. Following primary antibody incubations, the membranes were incubated with goat anti-rabbit or goat anti-mouse secondary antibody $(1: 1,000$; cat. no. A0239 or cat. no. A0216, respectively, Beyotime Institute of Technology, Haimen, China) for $1 \mathrm{~h}$. Protein bands were visualized by Enhanced Chemiluminescence Detection Reagent (Bio-Rad Laboratories, Inc., Hercules, CA, USA). The results were analyzed with Quantity One software 4.62 (Bio-Rad Laboratories, Inc.) and data were normalized based on GAPDH.

RNA isolation, cDNA synthesis and reverse transcriptionquantitative polymerase chain reaction ( $R T-q P C R)$. Total RNA from $10^{6}$ cells treated with indicated conditions was extracted using TRIzol reagent (Invitrogen; Thermo Fisher Scientific,Inc.) according to the manufacturer's protocol.cDNA was synthesized using the Reverse Transcription Reagent, according to the manufacturer's protocol (cat. no. N8080234, Thermo Fisher Scientific, Inc.) and RT-qPCR was performed with the SYBR Premix Ex Taq kit (cat. no. DRR041; Takara Biotechnology Co., Ltd., Dalian, China) according to the following PCR conditions: initial denaturation at $95^{\circ} \mathrm{C}$ for $30 \mathrm{sec}$ followed by 50 cycles of amplification at $95^{\circ} \mathrm{C}$ for $5 \mathrm{sec}$ and $60^{\circ} \mathrm{C}$ for $34 \mathrm{sec}$. The amplified fluorescent signal was detected by the ABI-7500 Sequence Detection System (Applied Biosystems; Thermo Fisher Scientific, Inc.). The primer sequences used in the study were as follows: MMP-9 (NCBI accession no. NM_004994.2), forward 5'-TGACGC CGCTCACCTTCACT-3', reverse 5'-CGCGCCATCTGCGTT TCCAA-3'; EMMPRIN (NCBI accession no. NM_001728.3), forward 5'-TTGGAGGTTGTAGGACCGGCGA-3', reverse 5'-TGGGACCCTGCCCTTCAAACCA-3'; and GAPDH (NCBI accession no. NM_001256799.2), forward 5'-CCG CATCTTCTTTTGCGTCGCC-3', reverse 5'-TCTCAGCCT TGACGGTGCCA-3'. The expression compared was using the $2^{-\Delta \Delta \mathrm{Cq}}$ method (24). All results were normalized with GAPDH. 
Gelatin zymography. Cells $\left(1 \times 10^{6}\right.$ cells/well $)$ in the logarithmic phase were seeded in 6-well plates and incubated in serum-free medium with or without $100 \mu \mathrm{M} \mathrm{A}-438079$ for $1 \mathrm{~h}$ at $37^{\circ} \mathrm{C}$ in a $5 \% \mathrm{CO}_{2}$ incubator, followed by incubation with $100 \mathrm{nM}$ PMA for an additional $48 \mathrm{~h}$ at $37^{\circ} \mathrm{C}$. Culture supernatants were collected and $20 \mu \mathrm{l}$ aliquots were loaded onto a $10 \%$ polyacrylamide gel containing $1 \mathrm{mg} / \mathrm{ml}$ gelatin. Following electrophoresis, gels were washed twice with $2.5 \%$ Triton X-100 (37 $\mathrm{C} ; 30 \mathrm{~min}$ each) and incubated at $37^{\circ} \mathrm{C}$ for $18 \mathrm{~h}$ in developing buffer comprising $10 \mathrm{mM}$ Tris base, $40 \mathrm{mM}$ Tris- $\mathrm{HCl}, 200 \mathrm{mM} \mathrm{NaCl}, 10 \mathrm{mM} \mathrm{CaCl}{ }_{2}, 0.02 \%$ Brij-35. Gels were subsequently stained with $0.5 \%$ (w/v) Coomassie Brilliant Blue R-250 for $2 \mathrm{~h}$ at room temperature, followed by destaining with a solution containing $50 \%$ methanol, $10 \%$ glacial acetic acid and 40\% water. MMP-9-digested regions were visualized as light bands against a dark background. An image of each gel was captured by an Odyssey Imaging System and analyzed by Image Studio 5.2.5 (LI-COR Biosciences, Lincoln, NE, USA).

Statistical analysis. Statistical analyses were performed using SPSS v18 software (SPSS Inc., Chicago, IL, USA). Three or more groups were compared using one-way analysis of variance (ANOVA) with Student-Newman-Keuls and Dunnett methods as post-hoc analysis if the result of ANOVA was significant. Data were presented as the mean \pm standard deviation. $\mathrm{P}<0.05$ was considered to indicate a statistically significant difference. All experiments were performed at least three times.

\section{Results}

$P M A$ treatment stimulated the expression of $P 2 X 7 R$ in a time-dependent manner. The use of PMA to induce THP-1 cells to differentiate into macrophages is a classical cell model that is widely used to explore the inflammatory function of macrophages in vitro $(25,26)$. THP-1 cells were treated with $100 \mathrm{nM}$ PMA for different incubation periods ranging between 6 and $48 \mathrm{~h}$. The protein expression level of P2X7R was measured by western blot analysis, which indicated that the level of PMA-stimulated P2X7R expression was in a time-dependent manner (Fig. 1). Therefore, the cells were treated with $100 \mathrm{nM}$ PMA for $48 \mathrm{~h}$ in the subsequent experiments.

Inhibition of $P 2 X 7 R$ reduces MMP-9 and EMMPRIN expression and MMP-9 activity in PMA-induced macrophages. THP-1 cells were pretreated with A-438079, a specific antagonist of P2X7R, for $1 \mathrm{~h}$, followed by incubation with $100 \mathrm{nM}$ PMA for $48 \mathrm{~h}$ to determine the effects of P2X7R inhibition on MMP-9 and EMMPRIN expression in PMA-induced macrophages. MMP-9 and EMMPRIN protein (Fig. 2A and B) and mRNA (Fig. 2C and D, respectively) expression levels were significantly increased in the PMA-induced macrophages, and the suppression of P2X7R expression by A-438079 treatment significantly inhibited the PMA-upregulated expression level of MMP-9 (Fig. 2). EMMPRIN, which is the most well-characterized and major cell surface regulator of MMP-9 (27), exhibited a similar reduction in expression as MMP-9 following suppression of P2X7R expression (Fig. 2). These results indicated that $\mathrm{P} 2 \mathrm{X} 7 \mathrm{R}$ inhibition affected the expression of EMMPRIN and MMP-9 in PMA-induced macrophages at both the protein and mRNA levels.
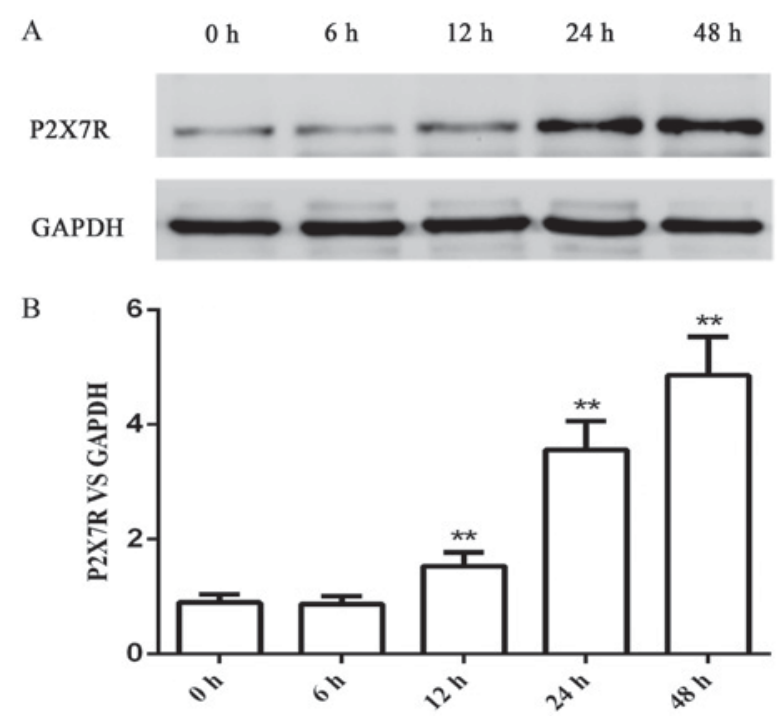

Figure 1. PMA-induced P2X7R expression at different time points in THP-1 cells. Following 0-48 h PMA induction, whole cell lysates were collected for western blot analysis of P2X7R and GAPDH protein expression (A) Representative blot of P2X7R and GAPDH expression at the various time points. (B) Densitometric analysis of P2X7R protein expression. For densitometry, the protein expression level of control $(0 \mathrm{~h})$ group was arbitrarily set as ' 1 ' in each blot, and P2X7R expression levels were normalized to the GAPDH. Data are expressed as the mean \pm standard deviation; $n=3 ;{ }^{* *} \mathrm{P}<0.01$ vs. 0 h control group. P2X7R, purinergic $2 \mathrm{X} 7$ receptor; PMA, phorbol 12-myristate 13-acetate.

The effects of P2X7R on the enzymatic activities of MMP-9 were examined by gelatin zymography. As previously reported (20), following staining with Coomassie Blue, an unstained transparent band was observed at $\sim 92 \mathrm{kDa}$; this band represented the theoretical size of the gelatin digested by MMP-9. In the THP-1-derived macrophages, MMP-9 activity was significantly increased in cells treated with PMA, compared to untreated control cells (Fig. 3A and B), and A-438079-inhibited expression of P2X7R significantly reduced MMP-9 activity.

P2X7R mediates AMPK activation induced by PMA. The potential mechanism associated with $\mathrm{P} 2 \mathrm{X} 7 \mathrm{R}$ regulation of MMP-9 and EMMPRIN expression in PMA-induced macrophages was determined by examining the potential involvement of the AMPK pathway. Cells were pretreated with A-438079 for $1 \mathrm{~h}$ and induced with PMA for another $48 \mathrm{~h}$. The protein expression levels of p-AMPK $\alpha$ and total AMPK $\alpha$ were examined by western blot analysis (Fig. 3C and D). PMA treatment induced the activation of AMPK $\alpha$ in THP-1 cells, and the phosphorylation of AMPK $\alpha$ was significantly reduced by A-438079 co-treatment. This result suggested that the inhibition of P2X7R inhibited AMPK $\alpha$ activation.

P2X7R inhibition suppresses mitogen-activated protein kinase (MAPK) pathway in PMA-induced THP-1 cells. Previous studies indicated that PMA treatment promoted the expression of EMMPRIN and MMP-9 by activating the MAPK signaling pathway (20). Therefore, whether P2X7R regulated the expression of EMMPRIN and MMP-9 through the MAPK pathway was examined. To verify this hypothesis, THP-1 cells were pretreated with A-438079 for $1 \mathrm{~h}$ prior to incubation with PMA 
A
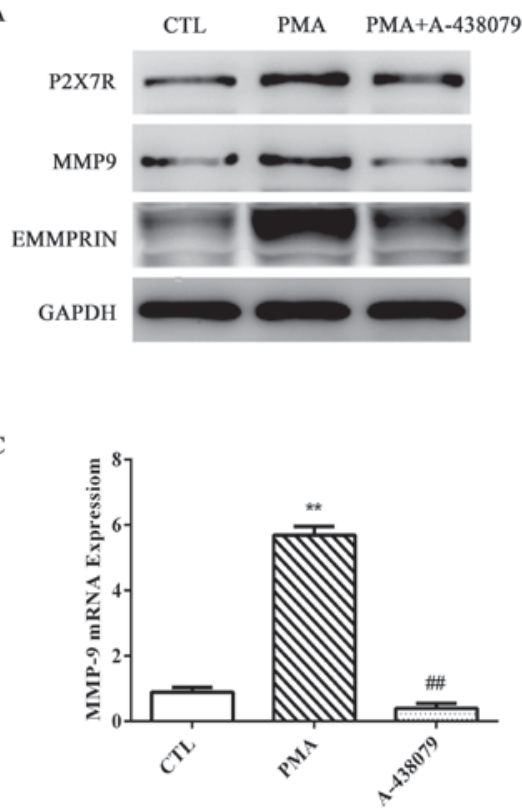

B
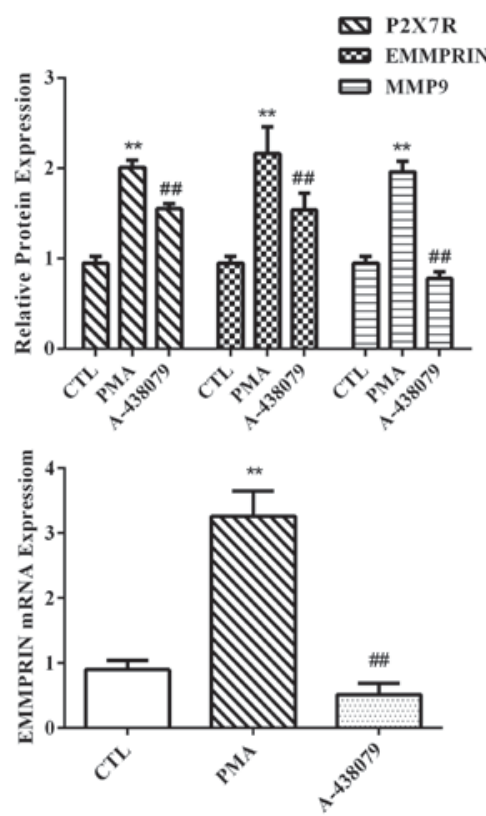

Figure 2. Inhibition of P2X7R by A-438079 decreases the expression level of EMMPRIN and MMP9 in PMA-induced THP-1 cells. (A and B) Protein expression levels of P2X7R, MMP-9, EMMPRIN and GAPDH were examined by (A) western blotting and (B) densitometric analysis. (C and D) mRNA expression levels of (C) MMP-9 and (D) EMMPRIN were measured by reverse transcription-quantitative polymerase chain reaction. Data are expressed as the mean \pm standard deviation; $n=3 ;{ }^{* *} \mathrm{P}<0.01$ vs. CTL group; ${ }^{\# \#} \mathrm{P}<0.01$ vs. PMA group. CTL indicates that cells incubated in a medium without PMA. CTL, untreated control group; EMMPRIN, extracellular matrix metalloproteinase inducer; MMP-9, matrix metalloproteinase 9; P2X7R, purinergic 2X7 receptor; PMA, phorbol 12-myristate 13-acetate.

A

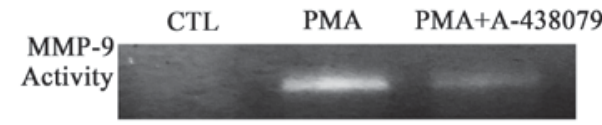

$\mathrm{C}$

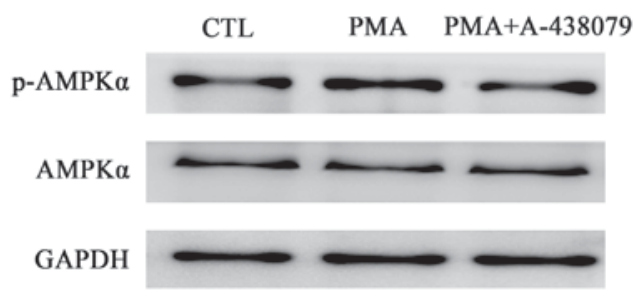

B

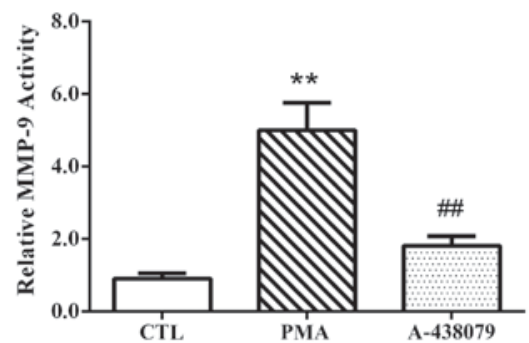

D

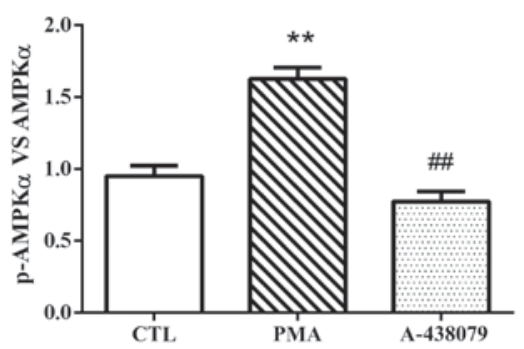

Figure 3. Inhibition of P2X7R by A-438079 suppresses the activation of MMP-9 and AMPK activation. (A and B) Effects of P2X7R inhibition on the activity of MMP-9 from cultured supernatant. THP-1 cells were pretreated with A-438079 prior stimulating with PMA (100 nM) for an additional 48 h; MMP-9 activities were detected by (A) gelatin zymography assay and (B) densitometric analysis. (C and D) Effects of P2X7R inhibition on total AMPK and p-AMPKo expression. THP-1 cells were treated with PMA or PMA + A-438079 and the protein level of total AMPK $\alpha$ and p-AMPK $\alpha$ were examined by (C) western blotting and (D) densitometric analysis. Data are expressed as the mean \pm standard deviation; $n=3 ;{ }^{* *} \mathrm{P}<0.01$ vs. CTL; ${ }^{\# \#} \mathrm{P}<0.01$ vs. PMA group. AMPK, 5'-AMP-activated protein kinase; CTL, untreated control group; MMP-9, matrix metalloproteinase 9; p, phosphorylated; P2X7R, purinergic 2X7 receptor; PMA, phorbol 12-myristate 13-acetate.

for $48 \mathrm{~h}$. The inhibition of P2X7R by A-438079 co-treatment significantly decreased the PMA-induced phosphorylation of ERK1/2, p38 MAPK and JNK (Fig. 4A-D). These results suggested that the MAPK pathway may be involved in the regulation of EMMPRIN and MMP-9 expression by P2X7R in PMA-induced THP-1 cells.

\section{Discussion}

Regulation of plaque stability is vital to patients with atherosclerosis, particularly in cases of thrombosis and fatal complications. Previous studies have suggested that the involvement of $\mathrm{P} 2 \mathrm{X} 7 \mathrm{R}$ in atherosclerotic regulation was 
A

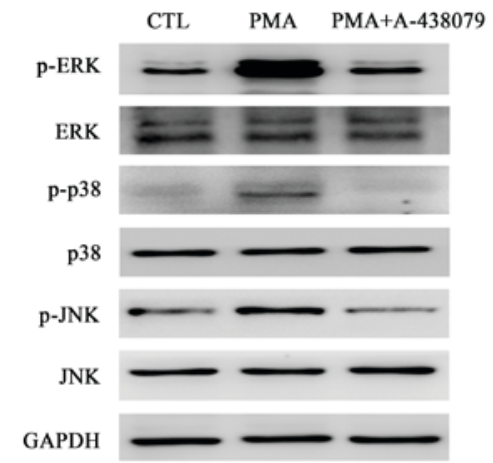

$\mathrm{C}$

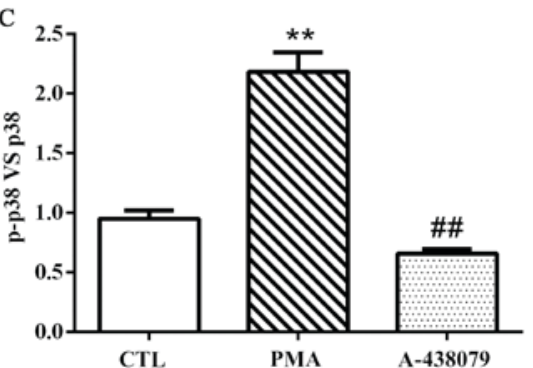

B
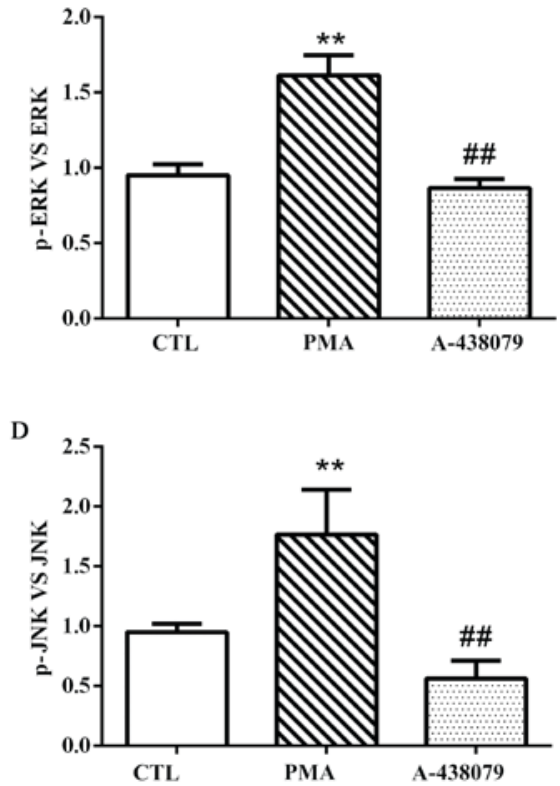

Figure 4. P2X7R regulates the phosphorylation of ERK1/2, p38 and JNK. (A) Protein expression levels of ERK, p-ERK, p38, p-p38, JNK, p-JNK and GAPDH were examined by western blot analysis. (B-D) Protein quantification was carried out by densitometric analysis. Proteins were normalized to the internal control GAPDH. Data are expressed as the mean \pm standard deviation; $n=3 ;{ }^{* *} \mathrm{P}<0.01$ vs. CTL group; ${ }^{\# \#} \mathrm{P}<0.01$ vs. PMA group. CTL, untreated control group; ERK, extracellular signal-regulated kinase; JNK, c-Jun N-terminal kinase; p, phosphorylated; P2X7R, purinergic 2X7 receptor; PMA, phorbol 12-myristate 13-acetate.

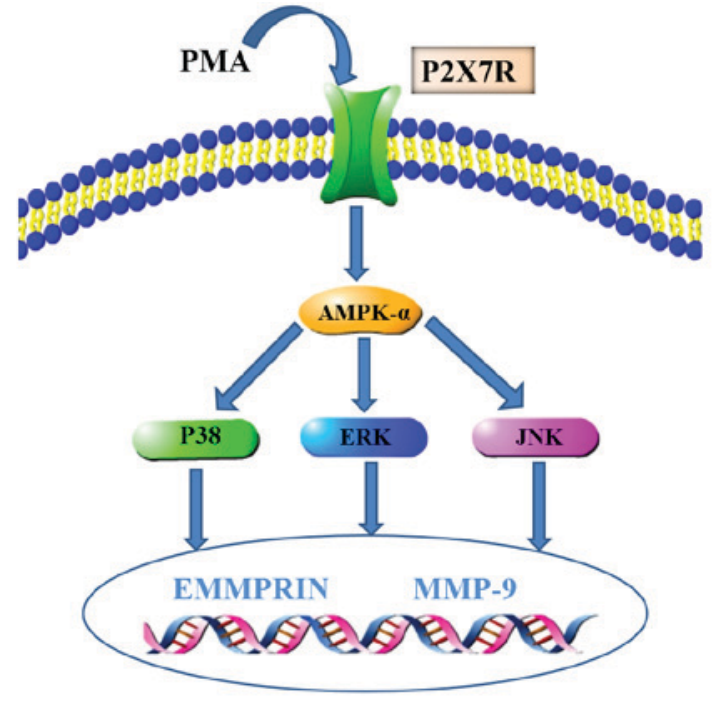

Figure 5. Model for the regulation of MMP-9 and EMMPRIN by P2X7R. PMA may induce EMMPRIN and MMP-9 expression in macrophages through the AMPK/MAPK pathway. P2X7R inhibition may attenuate the expression of MMP-9 and EMMPRIN by inhibiting the activation of AMPK-MAPK pathway. AMPK, 5'-AMP-activated protein kinase; EMMPRIN, extracellular matrix metalloproteinase inducer; MAPK, mitogen-activated protein kinase; MMP-9, matrix metalloproteinase 9; P2X7R, purinergic 2X7 receptor; PMA, phorbol 12-myristate 13-acetate.

through different targets, such as the NLRP3 inflammasome $(4,28)$. However, despite the general proinflammatory effects of P2X7R, the mechanism by which it mediates atheromatous progression has been poorly investigated. Additionally, the elevated expression levels of EMMPRIN and MMP-9 have been correlated with advanced atherosclerotic lesions, followed by plaque rupture and myocardial infarction $(13,29)$. The present study demonstrated that P2X7R inhibition by A-438079 significantly downregulated the expression of EMMPRIN and MMP-9 at the protein and mRNA levels, probably by suppressing the AMPK and MAPK pathways in PMA-induced THP-1 cells. Therefore, P2X7R may be a potential therapeutic target for ameliorating the development of atherosclerotic plaques.

$\mathrm{P} 2 \mathrm{X} 7 \mathrm{R}$ is considered to be only activated in circumstances in which the local concentration of ATP increases, such as infection and injury, or in tumor microenvironments (30). However, currently unknown allosteric modulators may serve a role in $\mathrm{P} 2 \mathrm{X} 7 \mathrm{R}$ activity in vivo by decreasing its $\mathrm{Km}$ for ATP so that P2X7R may be activated even at low nucleotide concentrations (2). Similar to this hypothesis, our previous research demonstrated that the expression of P2X7R is highly elevated when stimulated by PMA in monocytes-derived macrophages (31). Therefore, the present study this cell model was used to explore the underlying biological mechanism. Although there is no explicit association between PMA and ATP, it was speculated that the stimulation of PMA may influence the extracellular concentration of ATP, but this needs to be investigated further. The present results suggested the possibility of $\mathrm{P} 2 \mathrm{X} 7 \mathrm{R}$ serving a role in the differentiation of THP-1 cells from monocytes to macrophages, but this needs to be studied further.

Furthermore, the regulation between P2X7R and MMP-9 in different physiologic and pathologic processes has also been reported. For example, $\mathrm{P} 2 \mathrm{X} 7$ receptor activated by ATP stimulation in human peripheral blood mononuclear cells was revealed to rapidly increase MMP-9 release and thus enhanced extracellular MMP-9 activity (16). P2X7R 
was also demonstrated to be involved in the regulation of the blood-brain barrier by mediating MMP-9 activities and the degradation of the extracellular matrix $(32,33)$. The present results revealed that the inhibition of $\mathrm{P} 2 \mathrm{X} 7 \mathrm{R}$ expression may significantly inhibit the PMA-induced upregulation of MMP-9 expression and activity. In addition, EMMPRIN, as the major cell surface regulator of MMP-9, was also regulated by P2X7R in PMA-induced THP-1 cells.

To determine the molecular mechanisms by which P2X7R may regulate the expression of EMMPRIN and MMP-9 in differentiated macrophages, the level of phosphorylated AMPK $\alpha$ was investigated. A previous study revealed that the activation of AMPK $\alpha$ may be induced by PMA treatment (20). In addition, another study reported that P2X7R was able to mediate the activation of AMPK during autophagy induced by LL-37 in macrophages (34). On the basis of these results, the present study hypothesized that $\mathrm{P} 2 \mathrm{X} 7 \mathrm{R}$ may regulate the activation of AMPK $\alpha$ to adjust the levels of EMMPRIN and MMP-9 expression in PMA-induced macrophages. As expected, the inhibition of P2X7R expression in the present study led to the reduced activation of the AMPK $\alpha$ pathway, and the downregulation of EMMPRIN and MMP-9 expression. Consequently, AMPK $\alpha$ activation may be necessary for P2X7R to regulate the expression of MMP-9 and EMMPRIN in PMA-induced macrophages. Notably, our previous data indicated that compound $\mathrm{C}$ also suppressed the phosphorylation of MAPK signaling, including the ERK, JNK and p38 pathways in PMA-induced macrophages (20). Therefore, the activation of the AMPK pathway is the upstream of MAPK in THP-1 cells stimulated with PMA.

Furthermore, P2X7R serves an essential role in the regulation of MAPK pathways during physiological and pathological processes, such as sympathoexcitatory response in myocardial infarction (35) and the differentiation of bone marrow stem cells into osteoblasts (36-38). In the present study, the activation of the MAPK signaling pathway was examined in PMA-induced THP-1 cells and it was revealed that the inhibition of P2X7R significantly decreased the phosphorylation of ERK1/2, p38 MAPK and JNK in these macrophages. These results indicated that MAPK pathways may serve an essential role in the regulation of EMMPRIN and MMP-9 expression by P2X7R.

In conclusion, $\mathrm{P} 2 \mathrm{X} 7 \mathrm{R}$ expression was significantly increased in the PMA-induced macrophages, and the inhibition of P2X7R expression was followed by the downregulation of EMMPRIN and MMP-9 expression, which probably occurred through the suppression of AMPK and MAPK signaling pathway activation. AMPK, as an upstream activator of MAPK signaling, may be involved in the regulation of EMMPRIN and MMP-9 expression in PMA-induced macrophages (20). Therefore, the present study suggested that P2X7R may regulate EMMPRIN and MMP-9 expression through AMPK/MAPK signaling in PMA-induced macrophages and the schematic model is illustrated in Fig. 5. These data provided novel insights into the regulatory mechanisms of EMMPRIN and MMP-9 and suggested that P2X7R may be a potential strategy for combating plaque ruptures.

\section{Acknowledgements}

Not applicable.

\section{Funding}

This study was supported by The National Natural Science Foundation of China (grant no. 81670227), The Traditional Chinese Medicine Administration of Zhejiang Province (grant no. 2016ZA137) and The Wenzhou Science \& Technology Bureau (grant nos. Y20150036 and Y20150035).

\section{Availability of data and materials}

All data generated or analyzed during this study are included in this published article.

\section{Authors' contributions}

LL, ZH and WH conceived and designed the study. LL, SH, $\mathrm{ZW}, \mathrm{ZZ}$ and $\mathrm{JH}$ performed the experiments. $\mathrm{ZZ}$ and $\mathrm{ZH}$ analyzed and integrated the results. LL wrote the paper. ZZ, $\mathrm{JH}$ and $\mathrm{ZH}$ reviewed and edited the manuscript. All authors read and approved the manuscript.

\section{Ethics approval and consent to participate}

Not applicable.

\section{Consent for publication}

Not applicable.

\section{Conflict of interest}

The authors declare that they have no competing interests.

\section{References}

1. Ross R: ATHEROSCLEROSIS-An inflammatory disease. N Engl J Med 340: 115-126, 1999.

2. Bartlett R, Stokes L and Sluyter R: The P2X7 receptor channel: Recent developments and the use of P2X7 antagonists in models of disease. Pharmacol Rev 66: 638-675, 2014.

3. Baroja-Mazo A and Pelegrin P: Modulating $\mathrm{P} 2 \mathrm{X} 7$ receptor signaling during rheumatoid arthritis: New therapeutic approaches for bisphosphonates. J Osteoporo 2012: 408242, 2012.

4. Piscopiello M, Sessa M, Anzalone N, Castellano R, Maisano F, Ferrero E, Chiesa R, Alfieri O, Comi G, Ferrero ME and Foglieni C: $\mathrm{P} 2 \mathrm{X} 7$ receptor is expressed in human vessels and might play a role in atherosclerosis. Int J Cardiol 168: 2863-2866, 2013.

5. Peng K, Liu L, Wei D, Lv Y, Wang G, Xiong W, Wang X, Altaf A, Wang L, He D, et al: P2X7R is involved in the progression of atherosclerosis by promoting NLRP3 inflammasome activation. Int J Mol Med 35: 1179-1188, 2015.

6. Vandooren J, Van den Steen PE and Opdenakker G: Biochemistry and molecular biology of gelatinase B or matrix metalloproteinase-9 (MMP-9): The next decade. Crit Rev Biochem Mol Biol 48: 222-272, 2013.

7. Hsu S, Koren E, Chan Y, Koscec M, Sheehy A, Kolodgie F, Virmani $R$ and Feder D: Effects of everolimus on macrophage-derived foam cell behavior. Cardiovasc Revasc Med 15: 269-277, 2014.

8. Moustardas P, Kadoglou NP, Katsimpoulas M, Kapelouzou A, Kostomitsopoulos N, Karayannacos PE, Kostakis A and Liapis CD: The complementary effects of atorvastatin and exercise treatment on the composition and stability of the atherosclerotic plaques in ApoE knockout mice. PloS One 9: e108240, 2014.

9. Biswas C, Zhang Y, DeCastro R, Guo H, Nakamura T, Kataoka H and Nabeshima K: The human tumor cell-derived collagenase stimulatory factor (renamed EMMPRIN) is a member of the immunoglobulin superfamily. Cancer Res 55: 434-439, 1995. 
10. Yoon YW, Kwon HM, Hwang KC, Choi EY, Hong BK, Kim D, Kim HS, Cho SH, Song KS and Sangiorgi G: Upstream regulation of matrix metalloproteinase by EMMPRIN; extracellular matrix metalloproteinase inducer in advanced atherosclerotic plaque. Atherosclerosis 180: 37-44, 2005

11. Wang C, Jin R, Zhu X, Yan J and Li G: Function of CD147 in atherosclerosis and atherothrombosis. J Cardiovasc Transl Res 8: 59-66, 2015.

12. Major TC, Liang L, Lu X, Rosebury W and Bocan TM: Extracellular matrix metalloproteinase inducer (EMMPRIN) is induced upon monocyte differentiation and is expressed in human atheroma. Arterioscler Thromb Vasc Biol 22: 1200-1207, 2002.

13. Joghetaei N, Stein A, Byrne RA, Schulz C, King L, May AE and Schmidt R: The extracellular matrix metalloproteinase inducer (EMMPRIN, CD147)-a potential novel target in atherothrombosis prevention? Thromb Res 131: 474-480, 2013.

14. Riteau N, Gasse P, Fauconnier L, Gombault A, Couegnat M, Fick L, Kanellopoulos J, Quesniaux VFJ, Marchand-Adam S, Crestani B, et al: Extracellular ATP Is a danger signal activating P2X7receptor in lung inflammation and fibrosis. Am J Respir Crit Care Med 182: 774-783, 2010.

15. Huang C, Yu W, Cui H, Wang Y, Zhang L, Han F and Huang T: P2X7 blockade attenuates mouse liver fibrosis. Mol Med Rep 9: 57-62, 2014

16. Gu BJ and Wiley JS: Rapid ATP-induced release of matrix metalloproteinase 9 is mediated by the P2X7 receptor. Blood 107: 4946-4953, 2006.

17. Habets DD, Coumans WA, Voshol PJ, den Boer MA, Febbraio M, Bonen A, Glatz JF and Luiken JJ: AMPK-mediated increase in myocardial long-chain fatty acid uptake critically depends on sarcolemmal CD36. Biochem Biophys Res Commun 355: 204-210, 2007.

18. Wang X, Jia Q, Xiao J, Jiao H and Lin H: Glucocorticoids retard skeletal muscle development and myoblast protein synthesis through a mechanistic target of rapamycin (mTOR)-signaling pathway in broilers (gallus gallus domesticus). Stress 18 686-698, 2015

19. Iwanaka N, Egawa T, Satoubu N, Karaike K, Ma X, Masuda S and Hayashi T: Leucine modulates contraction- and insulin-stimulated glucose transport and upstream signaling events in rat skeletal muscle. J Appl Physiol 108: 274-282, 2010.

20. Cao J, Han Z, Tian L, Chen K, Fan Y, Ye B, Huang W, Wang C and Huang Z: Curcumin inhibits EMMPRIN and MMP- 9 expression through AMPK-MAPK and PKC signaling in PMA induced macrophages. J Transl Mad 12: 266, 2014

21. Byun HJ, Hong IK, Kim E, Jin YJ, Jeoung DI, Hahn JH, Kim YM, Park SH and Lee H: A splice variant of CD99 increases motility and MMP-9 expression of human breast cancer cells through the AKT-, ERK-, and JNK-dependent AP-1 activation signaling pathways. J Biol Chem 281: 34833-34847, 2006.

22. Lee SJ, Kim CE, Yun MR, Seo KW, Park HM, Yun JW, Shin HK, Bae SS and Kim CD: 4-Hydroxynonenal enhances MMP-9 production in murine macrophages via 5-lipoxygenase-mediated activation of ERK and p38 MAPK. Toxicol Appl Pharmacol 242: 191-198, 2010

23. Luo J, Lee S, Wu D, Yeh J, Ellamushi H, Wheeler AP, Warnes G, Zhang Y and Bo X: P2X7 purinoceptors contribute to the death of Schwann cells transplanted into the spinal cord. Cell Death Dis 4: e829, 2013.
24. Livak KJ and Schmittgen TD: Analysis of relative gene expression data using real-time quantitative PCR and the 2(-Delta Delta C(T)) Method. Methods 25: 402-408, 2001.

25. Auwerx J: The human leukemia cell line, THP-1: A multifacetted model for the study of monocyte-macrophage differentiation. Experientia 47: 22-31, 1991.

26. Qin Z: The use of THP-1 cells as a model for mimicking the function and regulation of monocytes and macrophages in the vasculature. Atherosclerosis 221: 2-11, 2012.

27. Wang QM, Wang H, Li YF, Xie ZY, Ma Y, Yan JJ, Gao YF, Wang ZM and Wang LS: Inhibition of EMMPRIN and MMP-9 expression by epigallocatechin-3-gallate through 67-kda laminin receptor in PMA-induced macrophages. Cell Physiol Biochem 39: 2308-2319, 2016.

28. Erlinge D and Burnstock G: P2 receptors in cardiovascular regulation and disease. Purinergic Signal 4: 1-20, 2008.

29. Newby AC: Metalloproteinase expression in monocytes and macrophages and its relationship to atherosclerotic plaque instability. Arterioscler Thromb Vasc Biol 28: 2108-2114, 2008.

30. Lenertz LY, Gavala ML, Zhu Y and Bertics PJ: Transcriptional control mechanisms associated with the nucleotide receptor P2X7, a critical regulator of immunologic, osteogenic, and neurologic functions. Immunol Res 50: 22-38, 2011.

31. Kong F, Ye B, Cao J, Cai X, Lin L, Huang S, Huang W and Huang Z: Curcumin represses NLRP3 inflammasome activation via TLR4/MyD88/NF- $\mathrm{KB}$ and P2X7R signaling in PMA-induced macrophages. Front Pharmacol 7: 369, 2016.

32. Yang $\mathrm{F}$, Zhao $\mathrm{K}$, Zhang X, Zhang J and Xu B: ATP induces disruption of tight junction proteins via il-1 Beta-dependent MMP-9 activation of human blood-brain barrier in vitro. Neural Plast 2016: 8928530, 2016.

33. Rubio-Araiz A, Perez-Hernandez M, Urrutia A, Porcu F, Borcel E, Gutierrez-Lopez MD, O'Shea E and Colado MI: 3,4-Methylenedioxymethamphetamine (MDMA, ecstasy) disrupts blood-brain barrier integrity through a mechanism involving P2X7 receptors. Int J Neuropsychopharmacol 17: 1243-1255, 2014

34. Rekha RS, Rao Muvva SS, Wan M, Raqib R, Bergman P, Brighenti S, Gudmundsson GH and Agerberth B: Phenylbutyrate induces 11-37-dependent autophagy and intracellular killing of mycobacterium tuberculosis in human macrophages. Autophagy 11: 1688-1699, 2015.

35. Wu Q, Xu H, Hao L, Ma G, Sun J, Song X, Ding F and Wang N: $\mathrm{P} 2 \mathrm{X} 7$ receptor regulates sympathoexcitatory response in myocardial infarction rats via NF-kappaB and MAPK pathways. Am J Transl Res 9: 4954-4962, 2017.

36. Okumura H, Shiba D, Kubo T and Yokoyama T: P2X7 receptor as sensitive flow sensor for ERK activation in osteoblasts. Biochem Biophys Res Commun 372: 486-490, 2008.

37. Li W, Li G, Zhang Y, Wei S, Song M, Wang W, Yuan X, Wu H and Yang Y: Role of P2 $x 7$ receptor in the differentiation of bone marrow stromal cells into osteoblasts and adipocytes. Exp Cell Res 339: 367-379, 2015.

38. Sathanoori R, Sward K, Olde B and Erlinge D: The ATP receptors P2X7 and P2X4 modulate high glucose and palmitate-induced inflammatory responses in endothelial cells. PLoS One 10: $\mathrm{e} 0125111,2015$. 